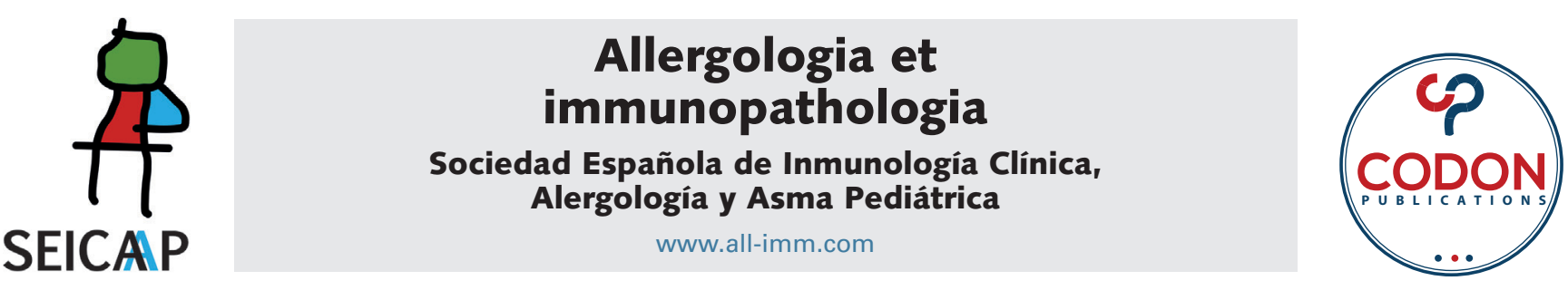

ORIGINAL ARTICLE

OPEN ACCESS @(1) (;)

\title{
The Preschool Asthma Risk Factors Scale: A predictive tool for asthma and respiratory symptoms among preschool children in Lebanon
}

\author{
Souheil Hallit ${ }^{\mathrm{a}, \mathrm{b}, * \dagger}$, Clara Rahme ${ }^{\mathrm{c}, \mathrm{t}}$, Hala Sacre ${ }^{\mathrm{b}}$, Mirna Waked ${ }^{\mathrm{d}}$, Pascale Salameh, \\ ${ }^{a}$ Faculty of Medicine and Medical Sciences, Holy Spirit University of Kaslik (USEK), Jounieh, Lebanon \\ IINSPECT-LB: National Institute of Public Health, Clinical Epidemiology and Toxicology, Beirut, Lebanon \\ 'Research Department, Psychiatric Hospital of the Cross, Jal Eddib, Lebanon \\ ${ }^{d}$ Department of Pulmonology, Saint Georges Hospital, Beirut, Lebanon \\ eUniversity of Nicosia Medical School, Nicosia, Cyprus \\ ${ }^{f}$ Faculty of Pharmacy, Lebanese University, Beirut, Lebanon
}

${ }^{\dagger}$ First co-authors

Received 28 December 2020; Accepted 2 May 2021

Available online 1 July 2021

\section{KEYWORDS asthma; risk factors; cohort; preschool children; gender; heating system; Lebanon}

\begin{abstract}
Background: The Preschool Asthma Risk Factor Scale (PS-ARFS) is a tool that enables clinicians to assess environmental exposure of preschool children, history of parental asthma, and dietary habits. The objective of this study was to evaluate the PS-ARFS ability to predict asthma diagnosis and respiratory symptoms 1 year after baseline assessment and improve the scale if necessary.

Methods: A prospective cohort study conducted between November 2018 and March 2019 in three Lebanese schools (from three different Lebanese Governorates) enrolled 515 preschool children aged 3-5 years. Parents completed a detailed questionnaire sent with their children (Phase 1; T0). All parents who participated in Phase 1 were invited to take the same survey by telephone (Phase 2; T1), 1 year later. The interview was conducted by one study-independent person. Of the total sample, $141(27.4 \%)$ children were lost to follow-up.

Results: Higher odds of asthma diagnosis at 1 year were significantly associated with playing outside (adjusted odds ratio $[\mathrm{aOR}]=3.958)$ and having a heating system in the bedroom $(\mathrm{aOR}$ $=6.986)$ at baseline, but inversely associated with the female gender $(\mathrm{aOR}=0.365)$. Based on those results, the improved PS-ARFS-I was generated. A higher PS-ARFS-I at T0 was significantly associated with higher odds of asthma at T1 $(\mathrm{aOR}=1.08 ; \mathrm{p}<0.001 ; 95 \%$ confidence interval $[\mathrm{Cl}]$ 1.05-1.10); similar results were obtained with the longer PS-ARFS $(\mathrm{aOR}=1.079 ; \mathrm{p}$ $<0.001 ; 95 \% \mathrm{Cl} 1.050-1.109)$. Moreover, among non-asthmatic children at baseline, the PS-ARFS score predicted wheezing and cough at T1 but not bronchial secretions; the PS-ARFS-I score at baseline did not predict symptoms at T1.
\end{abstract}

${ }^{*}$ Corresponding author: Souheil Hallit, Building 560, Street 8, Biakout, Lebanon. Email address: Souheilhallit@hotmail.com 
Conclusion: This study shows that the PS-ARFS-I and PS-ARFS could predict diagnosed asthma at 1-year follow-up. The PS-ARFS predicted respiratory symptoms (wheezing and cough) after 1 year among non-asthmatic children at baseline, suggesting that a score based on risk factors, measured early on, can predict better later symptoms and disease.

(c) 2021 Codon Publications. Published by Codon Publications.

\section{Background}

Asthma is the most widespread chronic disease in children of all ages, ${ }^{1}$ affecting more than 300 million people. ${ }^{2}$ Despite a worldwide decline in mortality, it is nevertheless subject to a high morbidity rate. ${ }^{3}$ According to the International Study on Asthma and Allergies in Childhood (ISAAC), asthma prevalence in children varies between 2.1 and $10 \% .{ }^{4}$ In Lebanon, previous research among children aged 13-14 years found an asthma prevalence of $8.3 \% .{ }^{5}$ However, data about prevalence in younger children (aged 3 to 5) are lacking.

Many researchers have examined factors that might increase the risk of childhood asthma. Genetic susceptibility can explain differences in the prevalence of asthma in different ethnic groups worldwide ${ }^{6}$ and environmental exposures. ${ }^{4}$ A meta-analysis of 33 studies found that maternal asthma triples the risk of childhood asthma. ${ }^{7}$ Premature birth $(<37$ weeks) and low birth weight $(<2.5 \mathrm{~kg})$ are also associated with the likelihood of childhood asthma. ${ }^{8}$ Previous studies have shown strong links between environmental factors and respiratory response. ${ }^{9}$ Indeed, children are particularly susceptible to environmental toxicants because of their growing and differentiating organs and tissues ${ }^{10}$; due to their frequent play activities on floors or carpets, this age group might be more exposed at home than older children and adults. ${ }^{9}$ However, children placed in an environment with a low natural microbial load can be vulnerable to allergic diseases due to under stimulation of the immune system. ${ }^{6}$ Parental smoking is another dangerous environmental exposure. ${ }^{6,10}$ Previous epidemiological research showed that children's susceptibility to maternal smoking raised the likelihood of having asthma and wheezing. ${ }^{11}$ Another study showed that maternal water pipe smoking was significantly and moderately related to allergic diseases. ${ }^{12}$

Asthma in adults and children over the age of 6 years is diagnosed based on a history of asthma symptoms and reversible spirometry-revealed obstruction of the airways. ${ }^{13}$ Spirometry is hard to perform in preschool children (aged 2-6 years), as they cannot do voluntary breathing maneuvers as successfully as older children and adults. ${ }^{14}$ Moreover, confirming asthma in preschool children seems to be more complicated because wheezing (the main symptom of asthma) is a common condition in children under 6 years of age. ${ }^{13}$

Symptoms of preschool asthma being nonspecific, it is difficult to ascertain which preschool children with asthma-like symptoms presently have and will develop the disease at school age. ${ }^{15}$ Hence, the Asthma Risk Factor Scale (ARFS), a 15-item tool, was created in 2018 to allow screening for asthma in Lebanese children aged 4-17 years, based on their exposure to selected risk factors and toxic substances and dietary habits (exposure to pesticides, mixing detergents, exposure to maternal medication intake, alcohol drinking, smoking during pregnancy and/or breastfeeding, current parental smoking status, history of asthma, and types of food). It showed appropriate validity and predictive properties. ${ }^{15}$ A similar score was created for preschool children exclusively (the Preschool Asthma Risk Factor Scale [PS-ARFS] scale) ${ }^{16}$ using the same risk factors of the ARFS with three additional variables, that is, playing outdoor, having a heating system in the bedroom, and attending a nursery. ${ }^{16}$ This new scale showed to have better properties; it was well correlated with concomitant asthma and had good positive and negative predictive values at T0 ( 88.7 and $84.3 \%$, respectively), ${ }^{16}$ but its ability to predict later asthma diagnosis was not assessed.

Therefore, this study aimed to test the ability of PS-ARFS in predicting asthma diagnosis and respiratory symptoms among preschool children 1 year after baseline assessment. The secondary aim was to generate an improved version of the scale.

\section{Methods}

\section{Study design}

A prospective cohort study conducted between November 2018 and March 2019 in three private schools located in urban regions from three (out of five) different Lebanese governorates recruited a convenient sample of 515 preschool children aged 3-5 years. Parents completed a detailed questionnaire sent with their children (Phase 1; T0). From January to April 2020, 1 year later, all parents who participated in Phase 1 were invited to take the same survey by telephone (Phase 2; T1). The interview was conducted by one study-independent person. Of the total sample, 141 (27.4\%) children were lost to follow-up.

\section{Sample size calculation}

The Epi-info software calculated a minimum sample of 232 children to allow for adequate bivariate and multivariate analyses, based on a population size of 360,000 children below 5 years old in Lebanon, ${ }^{17}$ a frequency of diagnosed asthma of $8.2 \%,{ }^{18}$ and a $95 \%$ confidence interval.

\section{Questionnaire and variables}

A pretested self-administered survey, inspired by the ISAAC questionnaire related to the respiratory symptoms (asthma, wheezing, cough, and bronchial secretion/expectoration), was used after a forward and back-translation procedure. ${ }^{19}$ The questionnaire used was the same that was used in previous studies. ${ }^{20-22}$ 
The first part of the questionnaire assessed the socio-demographic characteristics, including age, gender, region, education level of both parents, and number of rooms and number of persons living in the house. Parents' educational level was determined according to the number of years of schooling (illiterate, primary, complementary, secondary, university). The household crowding index, reflecting the socioeconomic status, ${ }^{23}$ was calculated by dividing the number of persons living in the house by the number of rooms apart from the kitchen and bathrooms.

The primary diagnosis of declared asthma and respiratory symptoms (wheezing, cough without flu, and bronchial secretions without flu) was defined as an affirmative answer to the question, "Has your doctor ever told you that your child has asthma/respiratory symptoms?" (One question was asked for each diagnosis). Parents also self-reported food, seasonal, and medication allergies based on a previous physician diagnosis.

The second part consisted of the PS-ARFS. It included the 15 questions of the ARFS and an additional three items specific for preschool children, that is, home heating system, playing outdoors, and attending nursery. It gathered information about family history of asthma and other known risk factors for asthma (home heating system, child history of recurrent otitis, house humidity or mold on the walls, attending a nursery, tonsillectomy, cardiac problems, and premature birth). It also included questions about smoking, type of smoking (cigarette or water pipe), alcohol consumption, medication intake during pregnancy and/or breastfeeding, in addition to occupational, regional, local, and domestic exposures to pesticides, and use of detergents (who uses them at home, types used, and whether or not they are mixed). The number of smokers at home determined passive smoking.

\section{Preschool Asthma Risk Factor Scale}

This 18-item scale was previously created to adapt the ARFS for preschool children. It is calculated as follows: PS-ARFS = $($ respiratory infections $\times 10)+($ playing in dust $\times 2)+($ playing on carpets $\times 2)+($ pulmonary problems in the child in the last 2 years $\times 25.5)+($ respiratory problems in the child before 2 years of age $\times 13.5)+$ (humidity in the house $\times 2.1$ ) $+($ asthma in mother $\times 6.3)+($ asthma in both parents $\times 9)$ $+($ history of reflux in the child $\times 2.9)+($ living in pesticides region $\times 2.6)+($ red meat daily $\times 2.8)+($ nuts $<2$ times/week $\times 0.4)+($ nuts $3-6$ times/week $\times 0.4)+$ (dairy products $<2$ times/week $\times 0.3)+($ dairy products $3-6$ times/week $\times 0.2$ ) $+($ playing outdoors $\times 2.4)+$ (heating system in the bedroom $\times 12.9)+($ attending a nursery $\times 2.5)$. In this formula, the presence of the variable is coded 1 and its absence 0 .

To answer the secondary objective of the study, the Improved PS-ARFS-I was created based on the logistic regression results; it included specific factors at baseline (Time 0 $=\mathrm{T} 0$ ) that predicted diagnosed asthma 1 year later (Time 1 $=\mathrm{T} 1)$.

\section{Statistical analysis}

Data were analyzed on Statistical Package for the Social Sciences (SPSS) (IBM Corp., Armonk, NY), version 23.
Descriptive statistics included frequencies (percentages) for categorical variables and means (standard deviations) for continuous variables. The Chi-square test evaluated the association between categorical variables and the presence/absence of asthma or other respiratory symptoms at T1; a kappa agreement $(k)$ was measured to examine the level of agreement between both measures (T0 and T1). Furthermore, logistic regressions were conducted to minimize possible confounding (adjustment done for all sociodemographic variables, pesticides exposure, playing outside, premature birth, humidity, mother's history of allergies, the use of detergents at home, child reflux, and place of the heating system), taking the presence/absence of diagnosed asthma at T1 as a dependent variable and the PS-ARFS scores at T0 and T1 and the PS-ARFS-I scores at T0 and T1 as independent variables. Additionally, a repeated-measures ANOVA was performed among non-asthmatic children at baseline, aiming to compare the probability of change in symptoms between baseline and T1, using the PS-ARFS scores at baseline. Statistical significance was set at $p<0.05$.

\section{Results}

Table 1 summarizes the sociodemographic characteristics of the children; out of 515 children enrolled at T0, 141 (27.4\%) were lost to follow-up. The mean age of children was 4.44 \pm 0.83 years, $46.0 \%$ were girls, the majority $(75.7 \%)$ lived in Mount Lebanon, and $8.2 \%(\mathrm{Cl} 95 \%$ 5.8-10.5) were diagnosed with asthma.

It is noteworthy that no significant difference was found between the included children and those lost to follow-up in terms of gender, asthma/wheezing/cough without flu/ bronchial secretions without flu diagnosis at T0, age, and house crowding index (Appendix Table 1 and Figure 1A).

\section{Symptoms and risk factors change between baseline and $\mathrm{T} 1$}

There was a statistical difference in the percentage of asthma risk factors between baseline and T1 for the following variables: playing on the carpet $\mathbf{( 7 1 . 4 \%}$ at baseline

Table 1 Sociodemographic characteristics of the children $(\mathrm{N}=515)$.

\begin{tabular}{ll}
\hline Variable & $N(\%)$ \\
\hline Sex & \\
$\quad$ Male & 54.0 \\
$\quad$ Female & 46.0 \\
Mohafaza/District & \\
$\quad$ Beirut & 16.9 \\
$\quad$ Mount Lebanon & 75.7 \\
North/South/Bekaa & 7.4 \\
Physician-diagnosed asthma (yes) & 8.2 \\
\hline & Mean \pm SD \\
\hline Age (in years) at baseline & $4.44 \pm 0.83$ \\
Household crowding index & $0.94 \pm 0.52$ \\
\hline
\end{tabular}




\begin{tabular}{|c|c|c|c|}
\hline Variable & $\begin{array}{l}\text { Lost to follow } \\
\text { up }(\mathrm{N}=141)\end{array}$ & $\begin{array}{c}\text { Included } \\
(\mathrm{N}=374)\end{array}$ & $\mathrm{p}$ \\
\hline Gender & & & 0.118 \\
\hline Male & $84(59.6 \%)$ & 194 (51.9\%) & \\
\hline Female & $57(40.4 \%)$ & $180(48.1 \%)$ & \\
\hline Asthma diagnosis at T0 & & & 0.366 \\
\hline No & 127 (90.1\%) & $346(92.5 \%)$ & \\
\hline Yes & 14 (9.9\%) & 28 (7.5\%) & \\
\hline Wheezing at T0 & & & 0.197 \\
\hline No & $92(65.2 \%)$ & $266(7.1 \%)$ & \\
\hline Yes & 49 (34.8\%) & $108(28.9 \%)$ & \\
\hline Cough without flu at T0 & & & 0.211 \\
\hline No & 119 (84.4\%) & 331 (88.5\%) & \\
\hline Yes & 22 (15.6\%) & $43(11.5 \%)$ & \\
\hline $\begin{array}{l}\text { Expectoration without } \\
\text { flu at T0 }\end{array}$ & & & 0.962 \\
\hline No & $128(90.8 \%)$ & $339(90.6 \%)$ & \\
\hline Yes & $13(9.2 \%)$ & 35 (9.4\%) & \\
\hline Age (in years) & $4.40 \pm 0.86$ & $4.46 \pm 0.81$ & 0.414 \\
\hline House crowding index & $0.92 \pm 0.54$ & $0.96 \pm 0.51$ & 0.501 \\
\hline
\end{tabular}

vs. $77.8 \%$ at T1), exposure to gas when cooking $(20.1 \%$ vs. $25.1 \%)$, and using central heating at home (18.7\% vs. $22.5 \%)$ (Appendix 2), despite a good agreement between baseline and T1 exposure [playing on the carpet $(\mathrm{k}=0.677)$, using gas while cooking $(\mathrm{k}=0.718)$, central heating in the house $(\mathrm{k}=0.657)$, and mother smoking water pipe $(\mathrm{k}=0.639)$ ]. Moreover, there was a significant decrease in the percentage of mothers who were currently smoking water pipe
(21.2\% vs. $17.4 \%$ ) (Figure $1 \mathrm{~A}$ and Appendix 2). No significant difference was found in the percentages of children with respiratory symptoms at baseline and T1 (Figure 1B). Additional details are presented in Appendix 2; other variables not displayed in the table did not show any significant difference between baseline and $\mathrm{T} 1$.

\section{Positive and negative predictive values}

At 14.20 (the cut-off value obtained in the study at T0), the results showed that the positive predictive value of the PS-ARFS at T0 with asthma at T1 was $65.5 \%$, whereas the negative predictive value was $85.4 \%$.

\section{Bivariate analysis of factors at baseline with asthma diagnosis at $\mathrm{T} 1$}

Asthma diagnosis at T1 was significantly associated with male gender compared with that of the female $(11.9 \%$ vs. $3.9 \%)$, children playing outside versus not (11.7\% vs. $4.0 \%)$, those who had a premature birth versus not $(25.0 \%$ vs. $7.1 \%)$, those living in homes with humidity and molds on walls versus not $(14.3 \%$ vs. $6.8 \%)$, those whose mothers did not use detergents to clean the house compared with those whose mothers did $(13.0 \%$ vs. $6.4 \%)$, and those who had a heating system in the bedroom compared to the sitting room and the whole house (Table 2 ).

\section{Multivariable analysis of factors at baseline associated with asthma diagnosis at T1}

The results of a forward logistic regression of factors at baseline associated with the child's asthma diagnosis at T1

(A)

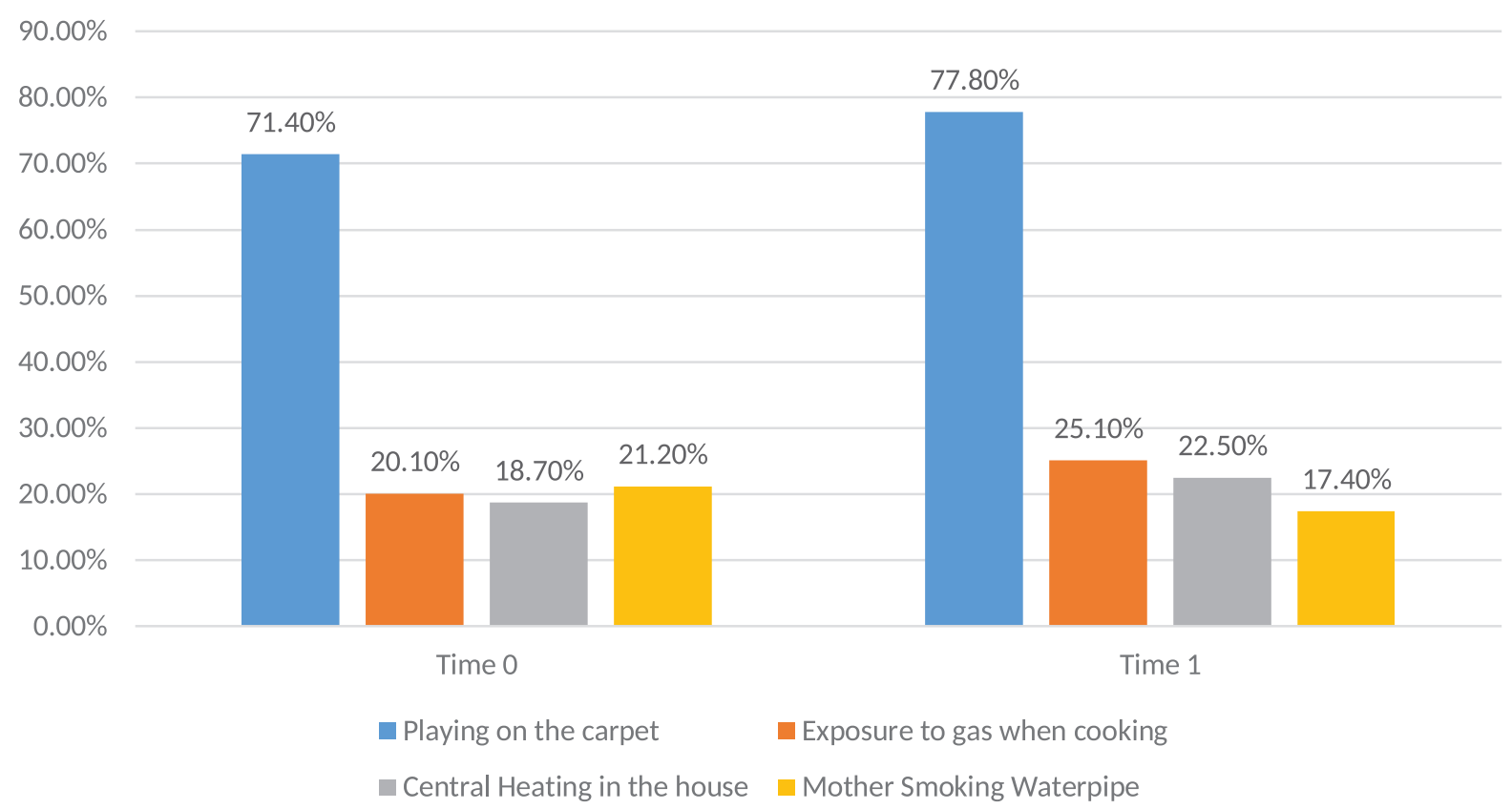

Figure 1 Exposure to selected risk factors between Baseline and T1. For playing on the carpet $(p=0.001)$, exposure to gas when cooking $(p=0.003)$, central heating in the house $(p=0.044)$ and mother smoking water pipe $(p=0.044)(A)$. Percentages of respiratory symptoms at BASELINE and T1. BASELINE = time of study beginning; T1 = evaluation after 1 year; $p>0.05$ for all (B). 
(B) $35.00 \%$

$30.50 \%$

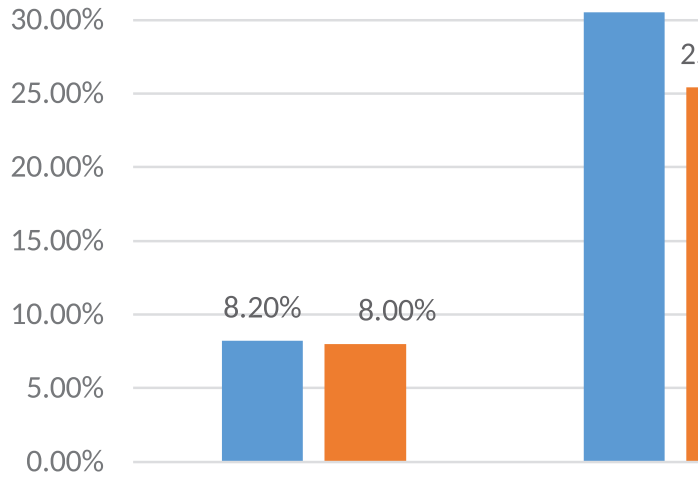

Asthma diagnosis

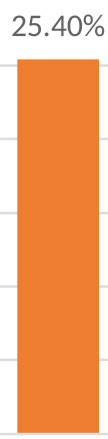

Wheezing

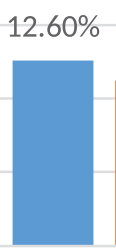

Cough

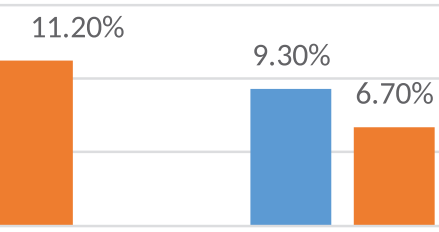

Expectoration

Figure 1 (Continued)

Appendix 2 Comparison of children at T0 and T1 in terms of respiratory symptoms.

\begin{tabular}{|c|c|c|c|}
\hline & \multicolumn{2}{|c|}{ Variable at T1 } & \multirow[b]{2}{*}{$\mathrm{p}$} \\
\hline & No & Yes & \\
\hline $\begin{array}{l}\text { Playing on carpet } \\
\qquad N=374(100 \%)\end{array}$ & $83(22.2 \%)$ & 291 (77.8\%) & 0.001 \\
\hline $\begin{array}{l}\text { No at TO N = } 107 \\
(28.6 \%)\end{array}$ & 72 (67.3\%) & 35 (32.7\%) & \\
\hline $\begin{array}{l}\text { Yes at T0 } N=267 \\
(71.4 \%)\end{array}$ & 11 (4.1\%) & 256 (95.9\%) & \\
\hline $\begin{array}{l}\text { Gas for cooking } \\
\qquad N=374(100 \%)\end{array}$ & 280 (74.9\%) & 94 (25.1\%) & 0.003 \\
\hline $\begin{array}{c}\text { No at TO N (18.7\%) } \\
=299(79.9 \%)\end{array}$ & 271 (90.6\%) & $28(9.4 \%)$ & \\
\hline $\begin{array}{l}\text { Yes at TO N = 75 } \\
(20.1 \%)\end{array}$ & 9 (12.0\%) & 66 (88.0\%) & \\
\hline $\begin{array}{l}\text { Central heating in the } \\
\text { house } N=374(100 \%)\end{array}$ & 290 (77.5\%) & $84(22.5 \%)$ & 0.044 \\
\hline $\begin{array}{l}\text { No at TO N = } 304 \\
(81.3 \%)\end{array}$ & 276 (90.8\%) & $28(9.2 \%)$ & \\
\hline $\begin{array}{l}\text { Yes at TO } N=70 \\
(18.7 \%)\end{array}$ & $14(20.0 \%)$ & 56 (80.0\%) & \\
\hline $\begin{array}{l}\text { Mother smoking } \\
\text { water pipe at T0 } \\
\mathrm{N}=373(100 \%)\end{array}$ & 308 (82.6\%) & 65 (17.4\%) & 0.044 \\
\hline $\begin{array}{l}\text { No at TO N = } 294 \\
(78.8 \%)\end{array}$ & $280(95.2 \%)$ & $14(4.8 \%)$ & \\
\hline $\begin{array}{l}\text { Yes at TO N = } 79 \\
(21.2 \%)\end{array}$ & $28(35.4 \%)$ & $51(64.6 \%)$ & \\
\hline
\end{tabular}

showed that playing outside compared with not (adjusted odds ratio $[\mathrm{aOR}]=3.958$ ), and having a heating system in the bedroom compared with having one in the sitting room $(\mathrm{aOR}=6.986)$ were significantly associated with higher odds of asthma diagnosis at T1. The female gender compared to
Table 2 Bivariate analysis of factors at BASELINE with asthma diagnosis at $\mathrm{T} 1$.

\begin{tabular}{|c|c|c|c|}
\hline Variables at baseline & $\begin{array}{l}\text { No asthma at } \\
\text { T1 }(\mathrm{N}=344)\end{array}$ & $\begin{array}{l}\text { Asthma at } \\
\mathrm{T} 1(\mathrm{~N}=30)\end{array}$ & $\mathrm{p}$ \\
\hline \multicolumn{3}{|l|}{ Gender } & 0.005 \\
\hline Male & $88.1 \%$ & $11.9 \%$ & \\
\hline Female & $96.1 \%$ & $3.9 \%$ & \\
\hline \multicolumn{3}{|c|}{$\begin{array}{l}\text { Living near a prairie sprayed with pesticides } \\
\text { at baseline }\end{array}$} & 0.080 \\
\hline No & $93.1 \%$ & $6.9 \%$ & \\
\hline Yes & $86.8 \%$ & $13.2 \%$ & \\
\hline \multicolumn{3}{|c|}{ Playing outside at baseline } & 0.006 \\
\hline No & $96.0 \%$ & $4.0 \%$ & \\
\hline Yes & $88.3 \%$ & $11.7 \%$ & \\
\hline \multicolumn{3}{|l|}{ Premature birth } & 0.004 \\
\hline No & $92.9 \%$ & $7.1 \%$ & \\
\hline Yes & $75.0 \%$ & $25.0 \%$ & \\
\hline \multicolumn{3}{|c|}{ Humidity at baseline } & 0.046 \\
\hline No & $93.2 \%$ & $6.8 \%$ & \\
\hline Yes & $85.7 \%$ & $14.3 \%$ & \\
\hline \multicolumn{3}{|c|}{ Allergy in any family member } & 0.073 \\
\hline No & $93.8 \%$ & $6.2 \%$ & \\
\hline Yes & $88.5 \%$ & $11.5 \%$ & \\
\hline \multicolumn{3}{|c|}{ Mother use of detergents at baseline } & 0.041 \\
\hline No & $87.0 \%$ & $13.0 \%$ & \\
\hline Yes & $93.6 \%$ & $6.4 \%$ & \\
\hline \multicolumn{3}{|l|}{$\begin{array}{l}\text { Child reflux at } \\
\text { baseline }\end{array}$} & 0.057 \\
\hline No & $92.8 \%$ & $7.2 \%$ & \\
\hline Yes & $82.8 \%$ & $17.2 \%$ & \\
\hline \multicolumn{3}{|c|}{ Place of heating system in the house } & 0.006 \\
\hline Sitting room & $90.7 \%$ & $9.3 \%$ & \\
\hline Bedroom & $66.7 \%$ & $33.3 \%$ & \\
\hline All the house & $94.5 \%$ & $5.5 \%$ & \\
\hline $\begin{array}{l}\text { Household } \\
\text { crowding } \\
\text { index }\end{array}$ & $0.96 \pm 0.50$ & $0.91 \pm 0.71$ & 0.605 \\
\hline
\end{tabular}

Numbers in bold indicate significant $p$-values; all other variables not displayed in this table did not show a significant difference between presence and absence of asthma diagnosis at T1. 
Table 3 Multivariable analysis: Forward logistic regression of factors at baseline associated with child's asthma diagnosis at $\mathrm{T} 1$.

$95 \%$

Confidence

\begin{tabular}{lcccc} 
Variable & $\mathrm{p}$ & $\mathrm{aOR}$ & \multicolumn{2}{c}{ Interval } \\
\hline Gender (females vs. males*) & $\mathbf{0 . 0 3 0}$ & 0.365 & 0.147 & 0.905 \\
Playing outdoor (yes vs. no*) & $\mathbf{0 . 0 0 6}$ & 3.958 & 1.476 & 10.618 \\
Placement of the heating & $\mathbf{0 . 0 0 6}$ & & &
\end{tabular}

system in the house

Bedroom vs. sitting room* $\quad \begin{array}{lllll}0.021 & 6.986 & 1.338 & 36.482\end{array}$

$\begin{array}{llllll}\text { All the house vs. sitting room* } & 0.103 & 0.498 & 0.216 & 1.150\end{array}$

*Reference group

aOR: adjusted odds ratio; BASELINE: Baseline; T1: evaluation after 1 year; numbers in bold indicate significant $p$-values; Nagelkerke R2=14.7\%; Hosmer and Lemeshow test $p=0.962$; children with asthma $\mathrm{N}=28$; variables entered in the final model: gender, living near a prairie sprayed with pesticides, playing outside, premature birth, humidity, mother's history of allergies, mother using detergents at home, child reflux, place of the heating system.

the male gender $(\mathrm{aOR}=0.365)$ was significantly associated with lower odds of asthma diagnosis at T1 (Table 3).

\section{Prediction of asthma at T1 with the scales}

The PS-ARFS-I is a three-item scale created based on the logistic regression results (Table 3 ), as follows: PS-ARFS-I $=($ gender $\times 0.5)+($ playing outdoors $\times 4)+($ heating system in the bedroom $\times 7$ ). In this formula, the presence of the variable is coded 1 and its absence as 0 ; as for gender, the male get one point, and the female get two points.

A forward logistic regression, taking the asthma diagnosis at T1 as the dependent variable and the PS-ARFS-I at $\mathrm{TO}$ and $\mathrm{T} 1$, in addition to age and house crowding index as independent variables, showed that a higher PS-ARFS-I at T0 was significantly associated with higher odds of asthma at T1 $(\mathrm{aOR}=1.08 ; \mathrm{p}<0.001 ; 95 \% \mathrm{Cl} 1.05-1.10)$. The PS-ARFS-I at T1 was not associated with asthma diagnosis at T1.

A forward logistic regression, taking the asthma diagnosis at T1 as a dependent variable and the PS-ARFS at T0 and $\mathrm{T} 1$, in addition to gender, age, and house crowding index as independent variables, showed that female gender $(\mathrm{aOR}=$ $0.261 ; p=0.007 ; 95 \% \mathrm{Cl} 0.098-0.695$ ) was significantly associated with lower odds of asthma at T1. A higher PS-ARFS at T0 was significantly associated with higher odds of asthma at $\mathrm{T} 1$ (aOR $=1.079 ; \mathrm{p}<0.001 ; 95 \% \mathrm{Cl} 1.050-1.109)$. The PS-ARFS at $\mathrm{T} 1 \mathrm{was}$ not associated with asthma diagnosis at T1.

Subgroup analysis: PS-ARFS scores at baseline, risk factors, and prediction of asthma symptoms at T1 among non-asthmatic children at baseline

A repeated-measures ANOVA was conducted taking the change in each respiratory symptom (wheezing, cough without flu, and bronchial secretions without flu), between baseline and T1, as a dependent variable, among children with no asthma at baseline. After adjusting the analysis over the sociodemographic characteristics (age, gender, and house crowding index), the PS-ARFS score at baseline was able to predict an increase in the probability of wheezing and cough at T1, but not bronchial secretions (Table 4; Models 1-3). The PS-ARFS-I score at baseline could not predict a change in respiratory symptoms at T1 (Table 4; Models 4-6).

\section{Discussion}

This prospective cohort study evaluated the factors associated with asthma and tested the ability of the PS-ARFS to predict respiratory symptoms and asthma diagnosis 1 year after baseline assessment. There was no significant difference between the included children and those lost to follow-up in terms of sociodemographic characteristics and respiratory symptoms, thus minimizing the selection bias.

Both PS-ARFS and PS-ARFS-I could predict asthma diagnosis 1 year after baseline assessment, with a shorter administration time for the improved scale (3 items vs. 18 items). However, the PS-ARFS, but not the PS-ARFS-I, could predict the increased probability of wheezing and cough in preschool children; in all cases, a risk scale measured early on can better predict what will happen later in life.

Besides, given that the subgroup analysis included non-asthmatic children at baseline, the PS-ARFS-I seems more focused on asthma, while the PS-ARFS is a more general measure of many risk factors for chronic respiratory symptoms. Although additional studies are necessary to assess this particular point, this study could confirm that the PS-ARFS predicts both asthma and chronic respiratory symptoms 1 year after baseline assessment, while the PS-ARFS-I predicts only asthma. Overall, our results are similar to those of previous research performed to test a score, the Clinical Asthma Prediction Score (CAPS), which could predict asthma in preschool children. The results showed that CAPS would guide shared decision-making to target the need for medical or non-medical treatments. ${ }^{24}$ Further studies should compare both the scales on a larger sample and assess the predictive validity of the PS-ARFS score in a new dataset.

Also, continuous exposure to multiple risk factors (items of the scale) would maintain a favorable ground for developing a chronic respiratory disease, turning eventually into asthma; among risk factors, there was only a decrease in mother water-pipe smoking, while several factors show an increase at T1 versus T0, which is expected to perpetuate asthma among children. Furthermore, playing outdoors was significantly associated with higher odds of asthma in preschool children at T1. The impact of increased exposure and inhalation of dust in this vulnerable population can contribute to respiratory symptomatology and allergic sensitivity. ${ }^{9}$ Indeed, developing countries are facing rapid population growth and increased outdoor air pollution, thus, increasing the global burden of asthma. ${ }^{25}$ It is hypothesized that this factor was associated with more odds of asthma during this year in particular. Indeed, all children did not go to schools and they stayed home during the data collection because of the protests that took place in 
Table 4 Repeated measures ANOVA of the PS-ARFS score among non-asthmatic children at baseline to predict T1 increase in child's asthma diagnosis and respiratory symptoms.

Model 1: Wheezing without flu at T1

\begin{tabular}{lccccc}
\hline Variable & Beta & $\mathrm{p}$ & \multicolumn{2}{c}{$\begin{array}{c}\text { 95\% Confidence } \\
\text { Interval }\end{array}$} & Partial Eta Squared \\
\hline PS-ARFS score at baseline & 0.012 & $<0.001$ & 0.008 & 0.017 & 0.079 \\
\hline
\end{tabular}

Model 2: Cough without flu at T1

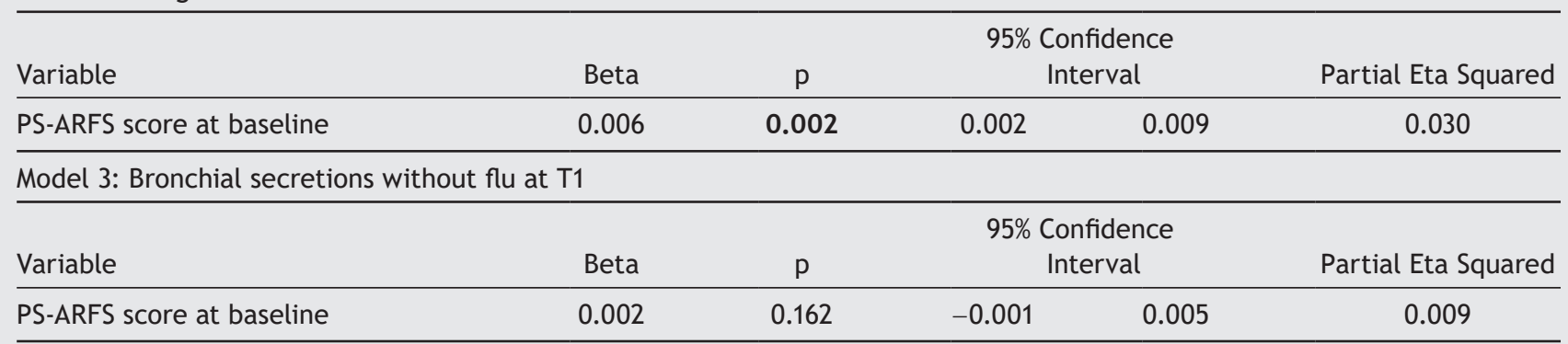

Repeated measures ANOVA of the PS-ARFS-IMPROVED score at T0 among non-asthmatic children at baseline to predict T1 increase in child's asthma diagnosis and respiratory symptoms.

Model 4: Wheezing without flu at T1

\begin{tabular}{|c|c|c|c|c|c|}
\hline \multirow{2}{*}{$\begin{array}{l}\text { Variable } \\
\text { PS-ARFS-IMPROVED score at baseline }\end{array}$} & \multirow{2}{*}{$\frac{\text { Beta }}{-0.008}$} & \multicolumn{3}{|c|}{$\begin{array}{l}\text { 95\% Confidence } \\
\text { Interval }\end{array}$} & \multirow{2}{*}{$\frac{\text { Partial Eta Squared }}{0.002}$} \\
\hline & & 0.437 & -0.028 & 0.012 & \\
\hline
\end{tabular}

Model 5: Cough without flu at T1

\begin{tabular}{lccccc}
\hline Variable & Beta & $\mathrm{p}$ & \multicolumn{2}{c}{$\begin{array}{c}\text { 95\% Confidence } \\
\text { Interval }\end{array}$} & Partial Eta Squared \\
\hline PS-ARFS-IMPROVED score at baseline & 0.011 & 0.150 & -0.004 & 0.027 & 0.006 \\
\hline Model 6: Bronchial secretions without flu at T1 & & & & & \\
\hline
\end{tabular}

PS-ARFS: Preschool Asthma Risk Factors Scale. Number in bold indicate significant p-values.

Lebanon from October to December 2019, followed by the sanitary lockdown imposed by the Lebanese government from mid-March until early June 2020. Staying home might have caused extended periods of playing outdoors where any constituent of dust susceptible to be re-suspended is likely to be inhaled. ${ }^{9}$

Moreover, using a central heating system in the bedroom compared with one in the sitting room was associated with higher odds of asthma after 1 year, similar to the results at baseline. ${ }^{16}$ Exposure to multiple substances found in indoor air has been associated with asthma exacerbation in children, with different levels of evidence. ${ }^{26} \mathrm{~A}$ review article about the association of indoor air pollution and asthma demonstrated the importance of evaluating indoor home air pollution sources as risk factors for asthma morbidity. ${ }^{27}$ The result of heating in the bedrooms versus heating all the house seems surprising. It could be related to other socio-economic factors or to a previous diagnosis of asthma in children who have heaters in the bedroom, therefore, inferring a reverse causality or the issue of heating type since the question asked was not clear enough. The confidence interval is broad because of the small sample in this study (nine children only). Moreover, the question itself might not be clear enough, which might lead the reader to assume that perhaps the question asked about ownership rather than heating frequency of use. Future studies with a larger sample are needed to confirm our findings.

\section{Clinical implications}

Early screening of asthma is compulsory in school children since starting treatment at earlier stages in this age group can preclude exacerbations and the worsening of lung function. A simple and easy-to-use scale can be a helpful clinical tool to screen children for future risk of developing asthma and asthma symptoms. This scale will also help parents take preventive measures and decrease exposure 
to modifiable risk factors to protect their children against developing asthma and chronic respiratory symptoms.

\section{Limitations}

Our research has some limitations. A selection bias could have occurred at baseline since the study included three urban schools only (no rural and no public schools selected) from three out of five Lebanese Governorates; therefore, the sample cannot represent the whole population. Moreover, the self-declaration of exposure to pesticides and other environmental factors (e.g., type and frequency of heating), symptoms, and diagnosis hampered the high level of evidence; an information bias is thus possible since it may not always be accurate to use a questionnaire among surrogate respondents (parents). Not all asthma-related variables could be evaluated in this study, which predisposes to residual confounding bias. Problems with understanding questions, recalling, and over or under-evaluating symptoms are also possible; however, the high concordance between T0 and T1 answers provides evidence of adequate reliability. A longer follow-up is needed to confirm our results since 1-year follow-up might not be satisfactory, especially due to the fact that some of the children are younger than others.

Our study also has some strengths. Although some kids were lost to follow-up, our results were not affected since there was no significant difference between children who remained in the study and those lost to follow-up. Moreover, the prospective nature of the study adds to the validity of the results, increasing causality likelihood, especially that our study objective was not to assess the prevalence and symptoms of the disease.

\section{Conclusion}

This study shows that the PS-ARFS and PS-ARFS-I could predict diagnosed asthma at 1-year follow-up. The PS-ARFS predicted respiratory symptoms (wheezing and cough) after 1 year among non-asthmatic children at baseline, suggesting that a score based on risk factors, measured early on, can predict better later symptoms and disease. Additional studies would be necessary to confirm our findings.

\section{Acknowledgements}

The authors would like to thank the parents who accepted to help us in this study, Mrs. Desirée Ghanem, Father Valentino Da Silva Ghoul, and Mr. Joseph Chahine for their help in the data collection. Special thanks to Ms Nelly Kheir for her help with the data collection and entry.

\section{Funding}

This study was funded by the Lebanese University. The funder had no role whatsoever in the design of the study, the collection, analysis, and interpretation of data and in writing the manuscript.

\section{Declarations}

\section{Ethics Approval and Consent to Participate}

This study was approved by the Psychiatric Hospital of the Cross Ethics and Research Committee (HPC-007-2019). The aim of the study was informed to each participant. A written consent was obtained from the children's parents.

\section{Consent for publication}

Not applicable.

\section{Availability of data and materials}

All data generated or analyzed during this study are not publicly available to maintain the privacy of the individuals' identities. The dataset supporting the conclusions is available upon request to the corresponding author.

\section{Competing interests}

The authors have no competing interests to disclose.

\section{Author contributions}

S.H. and P.S. conceived and designed the study. S.H. and P.S. involved to data interpretation and statistical analysis. S.H. and C.R. wrote the manuscript. H.S. critically revised the manuscript for intellectual content. All authors read and approved the final manuscript.

\section{References}

1. Asher I, Pearce N. Global burden of asthma among children. Int J Tuber Lung Dis. 2014;18(11):1269-1278. https://doi. org/10.5588/ijtld.14.0170

2. Ferrante G, La Grutta S. The burden of pediatric asthma. Front Pediatr. 2018;6:186. https://doi.org/10.3389/fped.2018. 00186

3. Waked M, Salameh P. Risk factors for asthma and allergic diseases in school children across Lebanon. J Asthma Allergy. 2008;2:1-7. https://doi.org/10.2147/JAA.S3844

4. Dharmage SC, Perret JL, Custovic A. Epidemiology of asthma in children and adults. Front Pediatr. 2019;7:246. https://doi. org/10.3389/fped.2019.00246

5. Musharrafieh U, Al-Sahab B, Zaitoun F, El-Hajj MA, Ramadan F, Tamim H. Prevalence of asthma, allergic rhinitis and eczema among Lebanese adolescents. J Asthma. 2009;46(4):382-387. https://doi.org/10.1080/02770900902777775

6. Ferrante G, La Grutta S. The burden of pediatric asthma. Front Pediatr. 2018;6:186-186. https://doi.org/10.3389/fped.2018.00186

7. Castro-Rodriguez JA, Forno E, Rodriguez-Martinez CE, Celedón JC. Risk and protective factors for childhood asthma: What is the evidence? J Allergy Clin Immunol Prac. 2016;4(6):11111122. https://doi.org/10.1016/j.jaip.2016.05.003

8. Beasley R, Semprini A, Mitchell EA. Risk factors for asthma: Is prevention possible? Lancet. 2015;386(9998):1075-1085. https://doi.org/10.1016/S0140-6736(15)00156-7 
9. Ramagopal M, Wang Z, Black K, Hernandez M, Stambler AA, Emoekpere $\mathrm{OH}$, et al. Improved exposure characterization with robotic (PIPER) sampling and association with children's respiratory symptoms, asthma and eczema. J Expo Sci Environ Epidemiol. 2014;24(4):421-427. https://doi.org/10.1038/jes.2014.27

10. Neuman Å, Hohmann C, Orsini N, Pershagen G, Eller E, Kjaer $\mathrm{HF}$, et al. Maternal smoking in pregnancy and asthma in preschool children: A pooled analysis of eight birth cohorts. Am J Respir Crit Care Med. 2012;186(10):1037-1043. https://doi. org/10.1164/rccm.201203-05010C

11. Kanoh M, Kaneita Y, Hara M, Harada S, Gon Y, Kanamaru H, et al. Longitudinal study of parental smoking habits and development of asthma in early childhood. Prev Med. 2012;54(1):9496. https://doi.org/10.1016/j.ypmed.2011.10.011

12. Waked M, Salameh P. Maternal waterpipe smoke exposure and the risk of asthma and allergic diseases in childhood: A post hoc analysis. Int J Occup Med Environ Health. 2015;28(1):147156. https://doi.org/10.13075/ijomeh.1896.00316

13. Lee YJ, Fujisawa T, Kim C-K. Biomarkers for recurrent wheezing and asthma in preschool children. Allergy Asthma Immunol Res. 2019;11(1):16-28. https://doi.org/10.4168/aair.2019.11.1.16

14. Jat KR. Spirometry in children. Prim Care Respir J. 2013;22(2):221-229. https://doi.org/10.4104/pcrj.2013.00042

15. Hallit S, Raherison C, Malaeb D, Hallit R, Waked M, Kheir N, et al. Development of an asthma risk factors scale (ARFS) for risk assessment asthma screening in children. Pediatr Neonatol. 2019;60(2):156-165. https://doi.org/10.1016/j.pedneo.2018.05.009

16. Hallit S, Sacre H, Kheir N, Hallit R, Waked M, Salameh P. Prevalence of asthma, its correlates, and validation of the Pre-School Asthma Risk Factors Scale (PS-ARFS) among preschool children in Lebanon. Allergol Immunopathol (Madr). 2021;49(1):40-49. https://doi.org/10.15586/aei.v49i1.25

17. Four, B., Hajjar, Y., Bibi, G., Chahab, M., \& Zaazaa, R. (2006). Comparative regional analysis of ECCE in four Arab countries (Lebanon, Jordan, Syria, and Sudan). Arab Resource Collective, 2007-2007 (Paper commissioned for the EFA Global Monitoring Report).

18. Hallit S, Salameh P. Exposure to toxics during pregnancy and childhood and asthma in children: A pilot study. J Epidemiol
Glob Health. 2017;7(3):147-154. https://doi.org/10.1016/j. jegh.2017.04.004

19. Asher M, Keil U, Anderson H, Beasley R, Crane J, Martinez F, et al. International Study of Asthma and Allergies in Childhood (ISAAC): Rationale and methods. Eur Respir J. 1995;8(3):483491. https://doi.org/10.1183/09031936.95.08030483

20. Hallit S, Raherison C, Abou Abdallah R, Hallit R, Salameh P. Correlation of types of food and asthma diagnosis in childhood: A case-control study. J Asthma. 2018;55(9):966-974. https://doi.org/10.1080/02770903.2017.1379535

21. Hallit S, Raherison C, Waked M, Salameh P. Association between caregiver exposure to toxics during pregnancy and childhood-onset asthma: A case-control study. Iran J Allergy Asthma Immunol. 2017;16(6):488-500.

22. Malaeb D, Hallit S, Sacre H, Hallit R, Salameh P. Factors associated with wheezing among Lebanese children: Results of a cross-sectional study. Allergol Immunopathol (Madr). 2020;48(6):523-529. https://doi.org/10.1016/j.aller.2020.02.003

23. Melki IS, Beydoun HA, Khogali M, Tamim H, Yunis KA, National Collaborative Perinatal Neonatal N. Household crowding index: A correlate of socioeconomic status and inter-pregnancy spacing in an urban setting. J Epidemiol Community Health. 2004;58(6):476-480. https://doi.org/10.1136/jech.2003.012690

24. Van der Mark LB, Van Wonderen KE, Mohrs J, Van Aalderen WM, Ter Riet G, Bindels PJ. Predicting asthma in preschool children at high risk presenting in primary care: Development of a clinical asthma prediction score. Prim Care Respir J. 2014;23(1):52-59. https://doi.org/10.4104/pcrj.2014.00003

25. Guarnieri M, Balmes JR. Outdoor air pollution and asthma. Lancet. 2014;383(9928):1581-1592. https://doi.org/10.1016/ S0140-6736(14)60617-6

26. Golden R, Holm S. Indoor air quality and asthma: Has unrecognized exposure to acrolein confounded results of previous studies? Dose Response. 2017;15(1):1559325817691159. https:// doi.org/10.1177/1559325817691159

27. Breysse PN, Diette GB, Matsui EC, Butz AM, Hansel NN, McCormack MC. Indoor air pollution and asthma in children. Proc Am Thorac Soc. 2010;7(2):102-106. https://doi. org/10.1513/pats.200908-083RM 